\title{
Dinâmica migratória dos senegaleses no norte do Rio Grande do Sul
}

\author{
João Carlos Tedesco* \\ Denize Grzybovski ${ }^{\star \star}$
}

\section{Introdução}

O tema das migrações internacionais vem ganhando espaço acadêmico, repercutindo no meio social, cultural e sendo central na esfera política de vários países que as têm em seu interior. 0 assunto é central também no Brasil, em várias áreas do conhecimento, em razão de o país vivenciar aspectos dessa realidade de imigrantes e emigrantes.

A presente nota de pesquisa, que tem como objetivo apresentar uma visão geral da dinâmica e das dimensões de um novo fluxo de imigrantes no Brasil, especificamente de senegaleses na região de Passo Fundo, no Rio Grande do Sul, é uma primeira aproximação ao tema no contexto regional e um convite à reflexão sobre fluxos migratórios na contemporaneidade. Para tanto, descrevem-se, a seguir, as questões metodológicas que orientaram a pesquisa empírica e suas limitações, bem como são apresentados os dados empíricos sobre dinâmica de inserção, convivência e integração dos senegaleses em Passo Fundo e região, relações de trabalho do imigrante, ganhos financeiros e desejo de empreender como elementos que alimentam a decisão de imigrar.

\section{Questões metodológicas de pesquisa}

A presente pesquisa foi desenvolvida no nível exploratório (GIL, 1999), com o objetivo de proporcionar uma visão geral, do tipo aproximativo, do fenômeno social, visando o aprofundamento em estudos posteriores. O espaço do levantamento foi delimitado pela comunidade de senegaleses na região de Passo Fundo (centro-norte do RS), que compõem uma imigração recente no interior do país e, em particular, para a região informada.

A fonte de dados são os imigrantes senegaleses e a pesquisa é do tipo "estudo de campo" (GIL, 1999), por ser mais flexível e permitir a observação dessa comunidade, com vistas a

\footnotetext{
* Doutor em Ciências Sociais, professor do Programa de Mestrado em História da Universidade de Passo Fundo (jctedesco@ upf.br).

${ }^{* *}$ Doutora em Administração, administradora, professora na Faculdade de Ciências Econômicas, Administrativas e Contábeis da Universidade de Passo Fundo (gdenize@upf.br).
} 
compreender estruturas de poder, formas de associação e o cotidiano de imigrantes. Os questionamentos giraram em torno das trajetórias que viabilizaram senegaleses em Passo Fundo e região, organização de vida, processos integrativos sociais, laborais e culturais, imagens e idealizações produzidas nesse espaço.

Na pesquisa empírica (realizada entre outubro de 2009 e março de 2011), empregaramse entrevistas individuais e coletivas, questionários e conversas informais nas ruas da cidade. Buscaram-se várias formas de acesso aos imigrantes, no sentido de obter informações, distribuir questionários, conversar mais diretamente sobre sua realidade em Passo Fundo e região, mas ocorreram limitações. As entrevistas eram mediadas por um líder e havia desconfiança por parte dos imigrantes em relação aos objetivos da pesquisa e ao não entendimento do idioma. Tentou-se estabelecer um diálogo em francês, idioma falado por todos eles, mas os senegaleses têm por hábito falarem ao mesmo tempo e, por vezes, usando o dialeto senegalês. Procurou-se, então, construir um espaço interativo de constantes visitas a pousadas onde os imigrantes se estabeleciam em maior grupo. Essa estratégia se revelou frutífera em função de sua dimensão coletiva (em duas oportunidades havia mais de 20 pessoas presentes nas entrevistas), diálogo produzido, confronto de ideias e interpretações em torno da realidade vivida.

Foram contatados imigrantes em outras cidades da região, como Getúlio Vargas, Marau, Erechim e Nova Araçá, em particular nas empresas e com vendedores que circulam pelas ruas. Também foi realizado levantamento junto ao Ministério do Trabalho e Emprego (MTE) e Delegacia da Polícia Federal em Passo Fundo. Não foi possível obter dados estatísticos mais precisos em razão da precariedade dos registros em nível de Brasil e da situação legal e funcional dos imigrantes, bem como, em âmbito local, em função da intensa rotatividade de imigrantes por causa de trabalhos na região, redes e vínculos formados no interior/ exterior ao grupo existente. Optou-se, então, pela análise qualitativa, narrativa de processos evidenciados, apreendidos pelas entrevistas.

\section{Resultados e discussões}

No acervo de entrevistados, constatou-se que a maioria dos senegaleses não tem domínio do português, fala pouco em francês e, quando estão reunidos, falam em dialeto regional. No trabalho, eles tentam se entender "por gestos". A maior parte dos senegaleses em Passo Fundo é constituída por homens solteiros, entre 25 e 40 anos, oriundos de pequenas cidades do Senegal (alguns são da capital Dakar). No período da pesquisa, foram identificadas cinco mulheres senegalesas no grupo, sendo quatro delas casadas, das quais, três estavam acompanhadas dos maridos.

A estimativa é de que havia em torno de 200 senegaleses na região; "só aqui nessa casa já passou mais de 100”, afirmou o líder do grupo, que imigrou há aproximadamente dez anos. A unidade regional do Departamento da Polícia Federal em Passo Fundo registrou a passagem de 380 africanos entre julho e dezembro de 2009, tempo determinado pela "lei da anistia" (BRASIL, 2009). 
Os motivos de estes imigrantes estarem em Passo Fundo são variados, mas a maioria deslocou-se de São Paulo após receber informação de conterrâneos que estavam trabalhando num abatedouro de aves, em Nova Araçá (RS). A informação que passou a circular entre imigrantes senegaleses, em âmbito nacional, é de que em Passo Fundo seria possível agilizar a documentação para a estada provisória no país. A partir daí, iniciou-se intenso fluxo (i)migratório de senegaleses, fato que se somou à possibilidade imediata de empregos em frigoríficos e empresas. A maioria dos imigrantes tem experiência em seu país em atividades agrícolas e de comércio, mas muitos também possuem habilidades técnicas, como pedreiro, carpinteiro, soldador, motorista, mecânico, padeiro, etc.

Em termos de trajetória, muitos senegaleses vieram direto da Argentina para Passo Fundo, com o objetivo de morar e trabalhar. Observou que existem canais/redes/territórios diversos que produzem e alimentam os fluxos; são redes que vão se constituindo por fatores de localização, regionalização, amizade, interconhecimento, etc. Tais redes no processo migratório podem ser entendidas como circulares; há pontos de origem e de destino; os de destino podem servir de origem para novos elementos constituidores de vínculos e que Ihes dão continuidade. As redes podem começar ainda no espaço de origem dos fluxos e irem se constituindo para frente, a partir de fatores informais e formais (tanto do campo empresarial, quanto do religioso, cultural e político), produzidos em razão das relações que o próprio processo migratório exige e demanda, bem como da realidade da identidade do imigrante e de seus vínculos com o espaço de origem (FUSCO, 2001).

No que se refere à religião, todos os entrevistados são islâmicos e, assim, passam a ser mão de obra demandada pelos frigoríficos exportadores de carnes de aves aos países árabes, os quais requerem a certificação Halal (CÂMARA, 2009) para comprovar o processo de matança dos animais. Também há presença de senegaleses em empresas de construção civil e de asfalto, indústria metalmecânica, pizzaria, padaria e funilaria.

Quanto ao mercado de trabalho, os imigrantes buscam as melhores oportunidades e, quando as encontram, simplesmente migram pela região. Juntos, eles exploram os benefícios econômicos e financeiros (salário, moradia, alimentação, transporte, outros) de uma proposta de trabalho e migram de uma para outra empresa com facilidade. Esse comportamento gera insegurança aos empresários: "Dos três que foram contratados, apenas um permanece na empresa e não sabemos por quanto tempo, devido aos costumes deles de não permanecerem por muito tempo num mesmo lugar e inclusive voltar para seu país de origem".

Os senegaleses revelaram satisfação no trabalho, apesar da dificuldade de serem "valorizados pela qualidade do trabalho" que prestam. Ainda que considerem o salário baixo, eles afirmam ser melhor que no Senegal: "Senegal não dá”; "Aqui mais trabalho"; "Senegal difícil".

Em termos econômicos, os senegaleses apresentam comportamento empreendedor, assumindo riscos, comercializando bijuterias e aceitando empregos temporários para formar fundos e realizar projetos de vida (“constituir meu próprio empreendimento no Senegal”, 
“sustentar família no Senegal”). O fluxo de remessas financeiras e o desenvolvimento de competências dos que passaram por Passo Fundo confirmam essa perspectiva.

Os imigrantes provocam algumas situações novas, interesses e dúvidas em razão de suas presenças, instituem redes informais de (entre)ajuda e consolidam uma dinâmica que integra e identifica a migração de senegaleses no Brasil. Vários entrevistados informaram que acabam chamando a atenção de moradores pelas suas vestimentas, formas grupais de andar na rua, venda de objetos, concentrações em espaços da cidade para lazer e encontros de oração.

Em relação aos aspectos culturais, os senegaleses conservam os hábitos religiosos, alimentares e de convivência em grupos. Entre eles, além da cordialidade e espontaneidade, é conservada a hierarquia familiar: permanece em pé quem é mais novo, seja nos espaços de convivência ou na calçada em frente às pousadas/moradias. Os entrevistados, de forma unânime, afirmam não se sentirem integrados à comunidade regional fora do âmbito pragmático do trabalho. Sentem, sim, o estranhamento mesclado com curiosidade pelos que os cercam e os veem. Uma administradora declarou, inclusive manifestando certo preconceito, que "é um povo de pouca confiança, pois entram e saem da empresa com tempo mínimo de trabalho; também você não sabe onde moram no Brasil e se tem família. Difícil confiar, né?”. Um entrevistado afirmou que "sai daqui pra trabalhar, retorna pra casa, nessa, é comer, orar e dormir; é sempre assim”. O líder desse grupo reconhece que o campo religioso permitiria produzir coesão/integração, consolação moral em razão das condições objetivas de vida de um imigrante distante de seus familiares e de seu país.

Foi possível perceber que, praticamente, não há lazer coletivo; em momentos que não estão trabalhando, eles telefonam para amigos e familiares no Senegal e no Brasil, assistem televisão e escutam música. A ausência de contato com a comunidade produz distanciamento, indiferença e ausência de fatores integrativos e de sociabilidade. Beccegato (1995) e Sayad (2008) colocam que não basta simplesmente adquirir algumas informações sobre usos, costumes ou aprender línguas estrangeiras para se fazer intercultura; deve-se adentrar, sim, para as problemáticas cognitivas, afetivas, sociais, desenvolver um pensamento aberto, flexível, inclusivo, que valorize os comportamentos reconhecidos no diálogo e no encontro. As identidades e identificações produzidas no interior das sociedades hospedeiras se (re)constroem pelos autóctones e estrangeiros também a partir de referenciais simbólicos (MEIHY; BELLINO, 2008).

É importante não esquecer, em termos estruturais e societais, que a reprodução do capital continua necessitando do trabalho para maximizar sua racionalidade de acumulação, inclusive ampliando o número de trabalhadores manuais; necessita de formas de superexploração da força de trabalho, servindo-se de elementos tradicionais étnico-culturais e de nacionalidades variadas, de imigrantes que alimentam mobilidades sociais, que "vieram pra trabalhar unicamente", como mencionou um líder do grupo de senegaleses, e, por isso, se submetem a situações muitas vezes precárias de vida e de relações de trabalho. A desqualificação e os estereótipos negativos que são produzidos tendem a fortalecer a ideia do intruso (RAMOS, 2003; WIEVIORKA, 2002). Os senegaleses são negros, pouco conhecidos na realidade 
regional e de religião muçulmana num período em que vêm se produzindo em vários países do mundo, em particular nos ocidentais, representações negativas em relação à mesma. Isso tudo, somado a um mercado de trabalho reduzido, tende a fazer com que imigrantes passem a sofrer exploração com maior intensidade de outros trabalhadores autóctones em atividades similares.

Os dados da pesquisa evidenciam que as relações de trabalho constituem uma dimensão central da vida do imigrante, pois fazem parte dos motivos da decisão de emigrar. A passagem de uma situação para outra com a intenção de melhorar a vida, instrumentalizada pelas questões de moradia, profissão, segurança econômica e aquisição de posses, passa a legitimar subjetivamente decisões migratórias. Por isso o desejo em torno do trabalho é intenso e justifica sua presença na região. A migração movimenta esse desejo e o migrante o procura, sujeitando-se ao cenário oposto do projetado para si no futuro. O sonho é alimentado pela dimensão metafórica da viagem e produzido pela esfera midiática e relacional dos que já foram, por fenômenos da sociedade global e por novas concepções em torno das fronteiras físicas, culturais e linguísticas (MEIHY; BELLINO, 2008).

Quanto à dimensão familiar, praticamente todos afirmam que possuem vínculos com familiares no Senegal (esposa, pais e avós). É por isso que a imigração deve ser entendida em relação tanto aos que saem como aos que ficam; há projetos e sonhos de ambos e, por isso, a ação torna-se familiar, afetiva e econômica, envolvendo também os que não migraram (SALES; REIS, 1999). Desse modo, os vínculos familiares vão se reconstituindo em espaços diferenciados. As saídas e permanências entre familiares revelam acordos internos, dinâmicas econômicas, sociais e afetivas, vínculos que vão se estendendo pelos territórios, porém, conservando obrigações, moralidades e sentimentos de família. É o caso de um imigrante que tem três mulheres e fez questão de dizer que isso só é possível se "o homem for capaz de sustentá-las". Para tanto, ele teria de "trabalhar cada vez mais", encontrar "um bom emprego".

O imigrante sempre foi visto como um trabalhador dependente, que se vincula no mercado de trabalho remunerado, contratado por alguém, num espaço de baixa qualificação. Ele é visto, concebido e projetado para ser, acima de tudo, força de trabalho não autônoma, como dependente, alguém que tem de trabalhar para outro alguém e tornar o trabalho otimizador para quem emprega. No caso de senegaleses na região, um empresário afirmou que "a vontade de realizar o desejo de ganhar dinheiro supera barreiras".

O recurso à mão de obra imigrante reflete interesses e estratégias de atores econômicos e da sociedade hospedeira. Não se pode esquecer que os imigrantes são pessoas que atravessam múltiplas fronteiras; em geral, por isso, não são vistos como pessoas que têm projetos, desejos de ir e voltar, permanecer e reconstruir suas vidas. Emigrar é cortar raízes, circular e preservar contatos; ser um emigrante conectado aqui e lá, ao mesmo tempo, nem aqui e nem lá; no fundo, um pluripertencimento aos territórios e às redes nacionais, do interior do país (AMBROSINI, 2008). Assim, os senegaleses são sujeitos reterritorializados 
parcialmente e, no mundo do trabalho, com tendência de maior exploração e precarização de relações, tempos, espaços, atividades e remunerações.

A renda resultante do trabalho é também um horizonte que alimenta a decisão de emigrar. Com ela é possível sustentar familiares no Senegal. As remessas financeiras mantêm vivas as relações entre quem partiu e quem ficou, veiculam os imigrantes e os familiares que permanecem no local de origem, atestam a densidade emotiva e simbólica das relações familiares ou não que se mantêm (AMBROSINI, 2010; TOLENTINO, 2009). Ainda, elas manifestam vínculos sociais de longa duração e contribuem para manter/alimentar múltiplas relações que viabilizam os fluxos migratórios, expressam a consciência da distância e a frustração da impossibilidade de contato face-a-face.

Trabalhar intensamente para sobrar dinheiro e enviar a familiares e/ou para empreender correlaciona-se com moral familiar, com o dever de família (RAMOS, 2003); transforma o imigrante num sujeito econômico transnacional. Nenhum senegalês informou que investe em Passo Fundo. Há os vendedores ambulantes que vendem mercadorias nas ruas e casas a partir de relações comerciais que produzem; em geral, são provenientes de São Paulo; não são produtos étnicos, ou seja, não possuem identidade com o grupo; são, sim, aqueles vendidos em pequenas lojas e/ou no comércio informal da cidade e região. Poucos conseguem investir; a maioria informou que dá para sustentar a família; quando fazem algum investimento, é no país/local de origem. O sacrifício em fazer poupança em outro país é sinônimo de possibilidade de investir no local de origem. Essa lógica entre parcimônia num local e investimento no outro é lugar comum em meio aos imigrantes, processo que auxilia na vida distante, permite sobreviver a situações adversas. Esse processo propicia fluxos constantes no interior do grupo doméstico.

Os imigrantes mantêm relações mais fáceis e mais além do pragmatismo com a pátriamãe e, ao mesmo tempo, estão em processo de aculturação na sociedade de destino. Desse modo, não dá mais para analisar a vida dos imigrantes apenas no que acontece no interior da sociedade maior, nos confins nacionais. Relações afetivas e familiares são recodificadas, redimensionadas e ressignificadas. Esses processos de reconstrução obedecem às condições efetivas e limitadas que o próprio cenário migratório apresenta. Nesse horizonte relacional transfronteiriço, vínculos continuam persistindo bem como intimidade e afetividade à distância facilitadas pelas novas tecnologias de comunicação.

\section{Considerações finais}

Nessa análise sobre senegaleses em Passo Fundo e região, buscou-se apresentar aspectos que constituem suas vidas. Enfatizamos ser uma realidade recente, que chama a atenção, desafia-nos a entender os processos que a mesma envolve. Constatou-se que esse grupo de imigrantes não está muito integrado à sociedade regional, mas encontra-se inserido no mundo do trabalho e isso é o que justifica suas ações e presença; há certa demanda social em torno do campo religioso, de espaços de habitação adequados e mais baratos, 
de remuneração mais satisfatória no espaço do trabalho. Os senegaleses demonstram ter qualificações no mercado de trabalho que os absorve. Trata-se de um grupo que se caracteriza pela mobilidade geográfica em termos regionais e no interior do país e expressa ainda muita desconfiança e curiosidade na população local.

Desse modo, são todos aspectos que demonstram que os imigrantes não são invisíveis. Com os recursos que possuem, os mesmos tentam encontrar espaços numa sociedade que ainda não está preparada para acolhê-los para além dos espaços funcionais do trabalho. Observou-se que múltiplas intencionalidades alimentam as estratégias dos imigrantes: há os que querem permanecer e "fazer a vida por aqui"; há os que pretendem transformar a experiência migratória em passagem de uma situação econômica para outra; existem outros que adotam horizontes de mobilidade entre os dois países em momentos que são considerados mais maximizadores em termos de ganhos e de atividades. Na realidade os imigrantes revelam que os territórios são móveis, assim como são culturas e pessoas. Isso se manifesta em múltiplos processos, atividades, situações, correlações, intercâmbios e vínculos.

Nesse sentido, a imigração poderá ser uma ocasião de enriquecimento social, de consciência da existência de capitais distribuídos socialmente, de um patrimônio cultural que pode enriquecer a todos por meio das línguas, culturas, credos, raças, representações simbólicas e mitos, valores e costumes.

\section{Referências}

AMBROSINI, M. Un’altra globalizzazione. Bologna: Il Mulino, 2008.

Richiesti e respinti. L’immigrazione in Italia. Come e perché. Milano: Il Saggiatore, 2010.

BECCEGATO, L. S. (a cura di). Interculturalità e scienze dell'educazione. Bari: Adriatica, 1995.

BRASIL. Decreto n. 6.893/2009. Regulamenta a Lei n. 11.961, de 2 de julho de 2009, que dispõe sobre a residência provisória para o estrangeiro em situação irregular no território nacional, e dá outras providências. Diário Oficial da União, Brasília, DF, 03 jul. 2009.

CÂMARA DE COMÉRCIO E INDÚSTRIA BRASIL IRAQUE. Exportando para o Iraque: estudo com... 2009. Disponível em: 〈http://www.brasiliraq.com.br/cms/arquivos/exportando_para_o_iraque_vf.pdf`. Acesso em: 05 nov. 2010.

DECIMO, F. Quando emigrano le donne. Bologna: Il Mulino, 2005.

FUSCO, W. Redes sociais na migração internacional: o caso de Governador Valadares. Dissertação (Mestrado) - Programa de Pós-Graduação em Sociologia, Instituto de Filosofia e Ciências Humanas. Universidade Estadual de Campinas, Campinas, 2001.

GIL, A. C. Métodos e técnicas de pesquisa social. 5. ed. São Paulo: Atlas, 1999.

MEIHY, J. C. S.; BELLINO, R. R. 0 estado dos imigrantes: o 28ำ estado brasileiro - um mercado de US\$ 50 bilhões. Rio de Janeiro: Elsevier, 2008.

RAMOS, P. S. Hospitalidade e migrações internacionais. São Paulo: Aleph, 2003.

SALES, T.; REIS, R. R. (Orgs.). Cenas do Brasil migrante. São Paulo: Boitempo, 1999. 
SAYAD, D. L'immigrazione o i paradossi dell'alterità. Verona: Ombre Corte, 2008.

TOLENTINO, N. C. Migrações, remessas e desenvolvimento: o caso africano. Instituto Superior de Economia e Gestão. Universidade Técnica de Lisboa, maio, 2009 (Socius working papers n. 09/2009). Disponível em: 〈http://hdl.handle.net/10400.5/1884〉. Acesso em: 15 jan. 2011.

WIEVIORKA, M. La differenza culturale. Roma-Bari: Laterza, 2002.

Recebido para publicação em 05/04/2011 Aceito para publicação em 19/09/2011 